\title{
O ENSINO MÉDIO POLITÉCNICO: A (IN) SEGURANCA EM OPERAR COM A PROPOSTA
}

\author{
THE POLYTECHNIC HIGH SCHOOL: THE (LACK OF) CONFIDENCE IN OPERATING \\ WITH THE PROPOSAL
ENSEÑANZA SECUNDARIA POLITÉCNICA: (IN)SEGURIDAD PARA EFECTUAR LA PROPUESTA

\author{
Cláudia Schvingel Klein Bühring* \\ (iD) https://orcid.org/oooo-ooo1-9110-5067 \\ Ieda Maria Giongo** \\ https://orcid.org/oooo-0002-1696-0642 \\ Angélica Vier Munhoz ${ }^{* * *}$ \\ https://orcid.org/oooo-0oo2-2644-043X
}

\author{
REVISTA PEDAGÓGICA \\ Revista do Programa de Pós-graduação em Educação da Unochapecó | ISSN 1984-1566 \\ Universidade Comunitária da Região de Chapecó | Chapecó-SC, Brasil \\ Como referenciar este artigo: BÜHRING, C. S. K.; GIONGO, I. M.; MUNHOZ, A. V. O ensino médio politécnico: \\ a (in) segurança em operar com a proposta. Revista Pedagógica, Chapecó, v. 22, p. 1-16, 2020. \\ DOI: http://dx.doi.org/10.22196/rp.v22io.4971
}

Resumo: Este artigo tem o intuito de compreender aspectos relativos à emergência da Proposta do Ensino Médio Politécnico para as Escolas Estaduais do Rio Grande do Sul. Os aportes teóricos que sustentaram a investigação são relativos a algumas ferramentas foucaultianas, em especial, enunciação e discurso. O material empírico da pesquisa foi gerado por meio de entrevistas semiestruturadas com três docentes que atuavam em cargos administrativos e a técnica de grupo focal desenvolvida com nove professores em uma escola de Ensino Médio, do interior do Vale do Taquari/RS. Também constituíram materiais de investigação o estudo dos documentos da referida proposta, a pesquisa em dois jornais de circulação no Vale do Taquari/RS e o diário de campo da pesquisadora. $\mathrm{O}$ estudo permitiu a emergência da unidade de análise que se configurou em torno da (in) segurança de operar com a Proposta. As enunciações acerca da Proposta em relação à (in) segurança geram, entre os professores, dúvidas, medo e resistência em operar com a pesquisa.

Palavras-chave: Ensino. Professor. Pesquisa. Politecnia.

Abstract: The present article aims to understand aspects of the emergence of the Proposal of the Polytechnic High School for the Rio Grande do Sul State schools. The theoretical framework that supported the research is related to some foucauldian tools, enunciation and discourse, in particular. The empirical material of the research was generated through semi-structured interviews with three teachers which worked at administrative positions and focus group technique with nine teachers from a high school at Vale to Taquari; study of the Proposal's documents; research in two newspapers and the researcher's diary. This research has allowed the emergence of the analysis unit which is configured around the (lack of) confidence in operating the Proposal. The enunciations about the Proposal regarding the (lack of) confidence generate, among teachers, doubt, fear and resistance to operate with the research.

Keywords: Teaching. Teacher. Research. Politecnia.

Resumen: Este artículo objetiva comprender aspectos relacionados con el surgimiento de la "Propuesta Pedagógica para la Enseñanza Secundaria Politécnica y Educación Profesional Integrada", para colegios de bachillerato pertenecientes al território de Rio Grande do Sul(RS), Brasil(BR). El enfoque teórico de la investigación se basó en el uso de algunas herramientas análiticas foucaultianas, específicamente, enunciación y discurso. El campo empírico se generó a través de entrevistas semiestructuradas con tres profesores, que para la fecha ocupaban cargos administrativos; ya para la técnica de grupo focal participaron nueve maestros de un colegio ubicado en un municipio del Vale do Taquari/ $R S / B R$. El análisis de los documentos relacionados con la Directriz Pedagógica se llevó a cabo, también, en dos periódicos de la región; así, como en el diario de campo de la investigadora. Este trabajo permitió la identificación de la unidad de análisis que se constituyó a partir de la (in)seguridad de efectuar la Propuesta Pedagógica. Las enunciaciones de los docentes sobre la Directriz, en relación a la (in)seguridad, evidenciaron en los docentes: dudas, miedo y resistencia para efectuar dicha proposición.

Palabras clave: Enseñanza. Profesor. Investigación. Politécnica 


\section{Introduzindo a temática}

O Estado do Rio Grande do Sul, em 2011, instituiu nas escolas estaduais o Ensino Médio Politécnico. A proposta, efetivada de forma gradativa, iniciou em 2012 e finalizou em 2016 e envolveu inicialmente o Primeiro Ano do Ensino Médio. Ela estava expressa em dois documentos base: a Proposta Pedagógica para o Ensino Médio Politécnico e Educação Profissional Integrada ao Ensino Médio, 2011-2014 e o Regimento Referência, 2012. Esses documentos contemplaram uma reorganização curricular por meio de debate com a comunidade escolar, culminando com a Conferência Estadual do Ensino Médio e da Educação Profissional em dezembro de 2011 (RIO GRANDE DO SUL, 2011-2014).

A Proposta Pedagógica para o Ensino Médio Politécnico e Educação Profissional Integrada ao Ensino Médio (2011-2014) propunha um ensino politécnico como domínio intelectual da técnica, em que a politecnia "[...] se constitui no princípio organizador da Proposta de Ensino Médio, seja na sua versão geral [...], ou na versão profissional, Educação Profissional integrada ao Ensino Médio" (RIO GRANDE DO SUL, 2011-2014, p. 14). A referida proposta articulava as áreas do conhecimento e suas tecnologias com os eixos: "[...] cultura, ciência, tecnologia e trabalho, [...]" (RIO GRANDE DO SUL, 2011-2014, p. 4). Esse ensino não era profissionalizante; a raiz estava no mundo do trabalho e nas relações sociais para a promoção da formação "[...] científico-tecnológica e sócio-histórica a partir dos significados derivados da cultura, tendo em vista a compreensão e a transformação da realidade" (RIO GRANDE DO SUL, 2011-2014, p. 14). Ademais,

Do ponto de vista da organização curricular, a politecnia supõe novas formas de seleção e organização dos conteúdos a partir da prática social, contemplando o diálogo entre as áreas de conhecimento; supõe a primazia da qualidade da relação com o conhecimento pelo protagonismo do aluno sobre a quantidade de conteúdos apropriados de forma mecânica; supõe a primazia do significado social do conhecimento sobre os critérios formais inerentes à lógica disciplinar (RIO GRANDE DO SUL, 2011-2014, p. 14).

No período da efetivação da nova proposta às Escolas Estaduais de Ensino Médio, iniciaram-se algumas manifestações - favoráveis e /ou contrárias - da sociedade gaúcha. Por conta disso, problematizou-se em uma dissertação de mestrado intitulada "O princípio do ensino pela pesquisa na Proposta do Ensino Médio Politécnico - Rio Grande do Sul", no período de 2014 a 2015, a emergência do Ensino Médio Politécnico do Estado do Rio Grande do Sul e

\footnotetext{
* Mestre em Ensino e doutoranda em Ensino pela Universidade do Vale do Taquari (Univates).. Bolsista PROSUP/ PROSUC-CAPES. Professora da Rede Municipal de Educação de Lajeado/RS. Endereço eletrônico: clau.dia1@hotmail.com

** Doutora em Educação pela Universidade do Vale do Taquari (Univates). Coordenadora do Programa de Pós-Graduação em Ensino na mesma instituição.

Endereço eletrônico: igiongo@univates.br

*** Doutora em Educação pela Universidade do Vale do Taquari (Univates). Professora na mesma instituição.

Endereço eletrônico: angelicavmunhoz@gmail.com
} 
a proposição da pesquisa escolar, "[...] como princípio pedagógico [...], [...] orientada e motivada pelos professores [...]" (RIO GRANDE DO SUL, 2011-2014, p. 21). O referido problema estava diretamente associado ao que evidenciava a Proposta Pedagógica para o Ensino Médio Politécnico, fazendo uso do documento da UNESCO sobre as Diretrizes Curriculares Nacionais para o Ensino Médio - 2011 no que refere à pesquisa

[...] como princípio pedagógico [...]: A pesquisa escolar, motivada e orientada pelos professores, implica na identificação de uma dúvida ou problema, na interpretação e elaboração dessas informações e na organização e relato sobre o conhecimento adquirido (UNESCO apud RIO GRANDE DO SUL, 2011-2014, p. 21, grifos nossos).

Neste sentido, os objetivos da dissertação de mestrado se concentravam em investigar como o ensino pela pesquisa se constituiria como princípio pedagógico da Proposta do Ensino Médio Politécnico do Rio Grande do Sul; analisar o que diziam os documentos sobre a pesquisa escolar no Ensino Médio Politécnico e, por fim, evidenciar as enunciações de um grupo de professores sobre o Ensino Médio Politécnico, em especial acerca da pesquisa escolar.

\section{Falando de metodologia}

A metodologia do trabalho foi elaborada a partir do momento que o problema e os objetivos estavam definidos. O estudo se utilizou de procedimentos metodológicos, como a entrevista semiestruturada com três professores ocupantes de cargos administrativos ligados ao Ensino Médio, e a técnica de grupo focal com nove professores das diferentes áreas do conhecimento de uma Escola de Ensino Médio Politécnico do Vale do Taquari/RS.

Ademais, realizamos o estudo dos documentos da Proposta Pedagógica para o Ensino Médio Politécnico e Educação Profissional Integrada ao Ensino Médio (20112014); do Regimento Referência das Escolas de Ensino Médio Politécnico da rede estadual (2012); do Parecer CNE/CEB No: 5/2011, que homologava as Diretrizes Curriculares Nacionais para o Ensino Médio e das Diretrizes Curriculares Nacionais da Educação Básica de 2013. Por fim, analisamos as reportagens expressas pela mídia em dois jornais de circulação no Vale do Taquari/RS e o diário de campo de uma das pesquisadoras.

Os excertos escrutinados dos materiais de pesquisa foram transcritos em forma de quadros durante a discussão da dissertação. Os três professores entrevistados foram nomeados como E1, E2 e E3, e os participantes da técnica de grupo focal, professor A (PA), professor B (PB), professor C (PC), professor D (PD), professor E (PE), professor F 
(PF), professor G (PG). É importante destacar que, para a escrita deste artigo, são utilizados somente excertos de sete professores participantes da técnica de grupo focal, pois no momento da sua elaboração somente esta quantidade de professores havia sido investigada. O estudo dos materiais de pesquisa permitiu a emergência de três unidades de análise, dentre as quais destacamos a segunda: A ${ }^{1}$ (in) segurança dos docentes participantes da pesquisa em operar com a Proposta. Esta por sua vez, possibilitou a discussão do artigo em questão nomeado "O Ensino Médio Politécnico: a (in) segurança em operar com a proposta”.

\section{A unidade de análise e seus resultados}

Na sequencia apresentamos a unidade de análise intitulada "A (in) segurança em operar com a proposta", com algumas interlocuções teóricas de Michel Foucault em torno de enunciação e discurso, assim como os resultados da investigação.

\subsection{A (in) segurança em operar com a proposta}

A proposta do Ensino Médio Politécnico gerou (in) segurança entre os professores participantes da pesquisa que foi evidenciada nos discursos e na mídia por meio de dois jornais de circulação no Vale do Taquari/RS. Durante um dos encontros de aplicação da técnica de grupo focal uma das pesquisadoras indagou sobre a proposta do Ensino Médio Politécnico e que conduziram as discussões dos professores. Entre os discursos dos professores estava a necessidade ou a falta de um ponto de partida, ou seja, em alguns instantes o sentimento expressado era de não saber mais por onde iniciar os planejamentos das aulas, o que levou a pesquisadora para a seguinte problematização: 'Vocês sentem falta de ponto de partida?'. A referida questão gerou os seguintes discursos:
1 A palavra '(in) segurança' será registrada desta forma ao longo do texto quando se tratar de discussões em torno dela colocando-a em destaque pelas autoras deste trabalho.

\section{Quadro 1. Excertos 1}

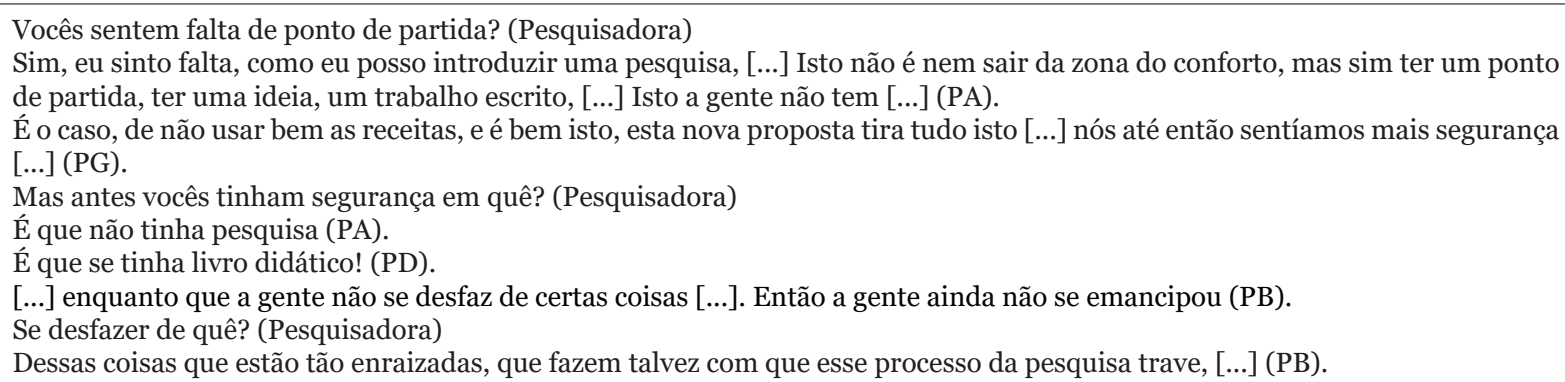

Fonte: Dados organizados pelas pesquisadoras, 2014.

A (in) segurança gerada entre os professores, conforme expressam os excertos anteriores, estava em especial, em torno da pesquisa escolar. Além de ser evidenciada 
entre os participantes da técnica de grupo focal, também a encontramos nos registros da mídia.

Quadro 2. Excertos 2

No ano passado havia muita resistência dos professores, mas que isso tem diminuído (A HORA, 22 ago. 2013, p. 4, grifo nosso).

Fonte: Dados organizados pelas pesquisadoras, 2014

A (in) segurança em operar com a proposta resultou em muitos questionamentos por parte de professores e comunidade escolar. Nas enunciações a seguir, os professores empregam a palavra 'como' para problematizar o desenvolvimento da proposta do Ensino Médio Politécnico, em especial a pesquisa.

Quadro 3. Excertos 3

Como vamos nos estruturar em tão pouco tempo? Vejo que vamos fazer experiência dentro de sala de aula e ainda nem estamos visualizando isso (O INFORMATIVO, 04 nov. 2011, p. 4, grifo nosso).

Mas como vou colocar isto em prática, como vou começar na prática? (Excerto extraído da técnica de grupo focal, PE, grifos nossos).

Fonte: Dados organizados pelas pesquisadoras, 2014

Ao analisar os materiais de pesquisa, encontramos, com relativa frequência, a repetição das palavras 'dúvidas', 'medo', 'resistência' quanto à proposta, a qual, de certa forma, ligava-se a outras que demonstravam segurança e insegurança. Essa relação é comprovada pelos excertos do quadro.

Quadro 4. Excertos 4

[...] só que a gente sempre está naquela insegurança, porque não é uma coisa pronta e acabada (Excerto extraído da técnica de grupo focal, $\mathrm{PB}$, grifo nosso).

Eu acho que o claro pode estar relacionado com a segurança (Excerto extraído da técnica de grupo focal, PB, grifo nosso).

[...] nós até então sentíamos mais segurança na forma como a gente trabalhava [...] (Excerto extraído da técnica de grupo focal, $\mathrm{PG}$, grifo nosso).

Fonte: Dados organizados pelas pesquisadoras, 2014

Essas enunciações nos levaram às seguintes problematizações: Que segurança os professores pedem? E, em algum dia, esses profissionais, no exercício de suas funções, sentiram-se seguros? As respostas explanadas durante a técnica de grupo focal à questão 'Mas antes, vocês tinham segurança em quê?' mostraram que a (in) segurança se referia à pesquisa, ou seja, ao exercício da docência por meio de ensino com/pela pesquisa, haja vista que trabalhavam com o livro didático. Ao reler as enunciações, percebemos o quanto esta docência estava ligada a 'exemplos'; a 'receitas' que, anteriormente, haviam dado certo; a um 'ponto de partida' e a uma 'zona do conforto'. Quais seriam os pontos de partida e a zonas de conforto que os educadores procuravam? Abaixo, mais excertos da técnica de grupo focal em torno dos entendimentos da 'zona de conforto': 
Quadro 5. Excertos 5

[...] o Ensino Politécnico [...] ele nos tirou da zona de conforto [...] (Excerto extraído da técnica de grupo focal, PG, grifo nosso). [...], sair da zona de conforto, talvez saindo dela, também a gente se emancipa (Excerto extraído da técnica de grupo focal, $\mathrm{PB}$, grifo nosso).

Fonte: Dados organizados pelas pesquisadoras, 2014

Já no quadro seguinte, percebe-se que a segurança, para o professor, estava ligada, a ausência do livro didático, pois nele estava determinado o que seria trabalhado com os alunos durante todo ano letivo.

Quadro 6. Excertos 6

No início do ano, tu já sabia como tu ia chegar no final do ano. Agora como mudou muita coisa. Isto não é. Isto não se tem mais. Tem sim, só que ali tu sabia que era isto, isto e aquilo. Agora, ou então a gente até faz tudo isso, só que não tem alguém que diz: é assim, isso está certo. Tu era acostumado a ver as coisas organizadas, prontas e agora não. A gente ganhou autonomia como escola, então talvez é isso também que nos causa insegurança (Excerto extraído da técnica de grupo focal, PB).

Fonte: Dados organizados pelas pesquisadoras, 2014

Seria essa (in) segurança algo desse tempo? Por que os professores necessitavam de segurança em seu trabalho docente? E em que ela consistia? Conforme um pesquisado, "[...] nós começamos a sentir firmeza, assim como um ponto seguro, pois as nossas angústias eram grandes até a apresentação dos primeiros trabalhos" (Excerto extraído da técnica de grupo focal, PG, 2014). O professor, ao se referir à "apresentação dos primeiros trabalhos", fazia menção à disciplina de Seminário Integrado ${ }^{2}$. Na sequência, destacamos algumas palavras ligadas à (in) segurança dos professores, tais como: 'despreparados', 'dificuldades', 'perdidos', 'inquietação', conforme consta no quadro:
2 O Seminário Integrado é uma disciplina curricular da Proposta do Ensino Médio Politécnico que passa a constar na carga horária da parte diversificada, proporcionalmente distribuída do primeiro ao terceiro ano. Nesta disciplina são organizados projetos de trabalho com a coordenação por parte do coletivo dos professores, sob a forma rotativa para garantir a necessária integração e diálogo entre as áreas do conhecimento. A elaboração dos projetos acontece a partir de pesquisa que explicite uma necessidade e/ou uma situação problema, dentro dos eixos temáticos transversais (RIO GRANDE DO SUL, 2011-2014).

Quadro 7. Excertos 7

Professores e alunos estão despreparados e enfrentam dificuldades em compreender a reforma (A HORA, 25-26-27 nov. 2011, p. 4, grifos nossos).

Os professores estão perdidos. Não sabem o que dar (A HORA, 22 ago. 2013, p. 4, grifo nosso).

Proposta que promete nova identidade a essa etapa do ensino provoca inquietação (O INFORMATIVO, o7 out. 2011, p. 31, grifo nosso).

Fonte: Dados organizados pelas pesquisadoras, 2014

As referidas frases nos levaram a investigar o problema com mais 'afinco', cujo passo foi novamente reler a entrevista concedida por E1 quando questionado sobre como a 'pesquisa' faria parte do cotidiano dos professores e como estes a desenvolveriam tendo em vista sua insatisfação. Segundo ele:

Quadro 8. Excertos 8

A primeira questão é a desacomodação. Suponhamos que todos na graduação desenvolveram um trabalho de conclusão, hoje muitos dos nossos professores fizeram uma pós-graduação, eles têm uma noção, mas precisam aprofundar (Excerto extraído da entrevista semiestruturada, E1).

Fonte: Dados organizados pelas pesquisadoras, 2014 
De fato, a (in) segurança evidenciada nas enunciações dos professores estava diretamente ligada ao que expressavam a Proposta para o Ensino Médio Politécnico e o Parecer $n^{0}$ 5/2011 acerca da pesquisa.

Quadro 9. A pesquisa escolar

Como metodologia, a pesquisa pedagogicamente estruturada possibilita a construção de novos conhecimentos e a formação de sujeitos pesquisadores, críticos e reflexivos (RIO GRANDE DO SUL, 2011-2014, p. 21).

Fonte: RIO GRANDE DO SUL, 2011-2014

Os documentos não deixam dúvidas sobre a função dos professores durante o processo de efetivação da pesquisa escolar. Seria essa a causa da (in) segurança, já que afirmavam não estarem preparados para trabalhar a nova Proposta de Governo? Ademais, durante a análise dos procedimentos metodológicos, constatamos que a (in) segurança estava ligada ao fato de os docentes não terem formação para trabalhar com a proposta, em especial com pesquisa, tornando-se um desafio, conforme os excertos do quadro a seguir.

\section{Quadro 10.Excertos 9}

[...] e que a maioria dos professores não aprendeu a pesquisar na sua formação [...] (Excerto extraído da entrevista semiestruturada, E3, grifo nosso).

É claro que com a novidade, a gente sai um pouco do eixo a que se estava acostumado, mas o desafio é encarado (O INFORMATIVO, o6 abr. 2013, p. 17, grifo nosso).

Fonte: Dados organizados pelas pesquisadoras, 2014

Já nas entrevistas semiestruturadas os professores expressaram que o processo de preparação da proposta se fez em momentos de discussão e formação nas comunidades escolares, conforme mostra a resposta à pergunta "Como esta proposta chegou ao conhecimento dos professores?":

Quadro 11. Excertos 10

Ela chega em 2011, a partir de julho de 2011, onde a Secretaria de Educação elaborou, junto com as Coordenadorias, um
documento básico, sugestão, [...]. Aí se começa a discutir com as direções, a apresentar a proposta básica, para a partir dela
construir uma proposta de trabalho consistente e enriquecê-la com mais dados naquele momento, daquele público, que está
ai. Então, nós da $3^{\text {a }}$ Coordenadoria, e como todos as outras coordenadorias tiveram orientações da SEC de discutir isto, e
colocar isto no meio dos alunos, dos funcionários, professores e pais também discutir com todos os segmentos. [...]. Em todos
os municípios nós realizamos a conferência, nós percebemos que nem em todas as escolas fizeram a discussão, mas mandaram
representantes (Excerto extraído da entrevista semiestruturada, E1, grifos nossos).

Fonte: Dados organizados pelas pesquisadoras, 2014

O excerto anterior revela o processo de mobilização por meio de 'Conferências' para desenvolver a proposta nas escolas. Além disso, para o entrevistado E1, o movimento de "discussão" na escola não aconteceu para todos. Ao ser questionado se "[...] teve espaço de discussão dos documentos na escola?", respondeu que "A partir das Conferências, das falas que a gente ouviu, a gente fez algumas mudanças, da questão do tempo, da quantidade dos períodos" $(E 1,2014)$. E, nesse momento, 
perguntamos se "Seria uma adequação dos documentos?” Segundo ele:

Quadro 12. Excertos 11

Seria uma adequação à realidade aquilo que os professores estavam percebendo. Por exemplo, o documento base trazia $25 \%$ da carga horária, mais de $25 \%, 40 \%$ da carga horária da parte diversificada, foi diluído, foi sugestão das escolas e depois a discussão terminou em dezembro daquele mesmo ano, em 2011 com uma conferência estadual, de todo o Estado, todas as coordenadorias, onde se fez depois disto o documento final (Excerto extraído da entrevista semiestruturada, E1).

Fonte: Dados organizados pelas pesquisadoras, 2014

Ainda na entrevista, ao lermos para o entrevistado a passagem da Proposta Pedagógica (2011-2014) - “[...] desenvolver consciências críticas capazes de compreender a nova realidade e organizar-se para construir a possibilidade histórica de emancipação humana" (p. 14), indagamos: Quem desenvolve? Quem prepara o professor? De acordo com E1:

Quadro 13. Excertos 12

A própria mantenedora ofereceu inúmeros seminários e encontros, cursos para contribuir com a formação desta consciência e destes conceitos e também dentro da escola, a escola recebeu recurso extra, além do que estavam recebendo, especificamente para trabalhar a formação, ai o professor dentro da sua carga horária de planejamento de reunião, de formação continuada, $30 \%$ deveria ter semanalmente ter estudo na escola, discussão, análise, a nossa orientação que fosse feito com a universidade, as escolas e professores também tem que buscar isto, está sendo oferecido pela mantenedora condições para que isto aconteça, tinham, 16h aula e passaram a ter 14 aulas e ainda tem 3 horas atividade para cumprir em casa, mas cumprem 4 para cada 20 horas na escola (Excerto extraído da entrevista semiestruturada, E1).

Fonte: Dados organizados pelas pesquisadoras, 2014.

Essa resposta nos levou a formular, ao mesmo professor, uma pergunta que não estava programada: "O que você fala, seria formação em serviço?". "Sim, [...] estudo em serviço, formação em serviço, a escola deve buscar professores que trabalhem conhecimentos da área, de como melhorar, de como trabalhar projetos, pesquisa" (Excerto extraído da entrevista semiestruturada, E1, 2014). Assim, novamente o questionamos: "Como a pesquisa irá fazer parte do cotidiano dos professores? Como os professores desenvolverão a pesquisa se dizem que não foram 'formados' para isso"? As respostas foram as seguintes:

\section{Quadro 14. Excertos 13}

Eu acho que devem estar desestabilizados, e quem não está não vai aprender a fazer, não vai buscar, a primeira questão é a desacomodação, devem se ater como professores, ter esta consciência, este espírito de responsabilidade de que precisam cumprir com o juramento que fizeram na formatura e como um sonho que tiveram ao fazer o concurso público do estado [...]. (Excerto extraído da entrevista semiestruturada, E1).

Fonte: Dados organizados pelas pesquisadoras, 2014

O referido professor acrescentou que "Muitos professores estão na resistência, sempre fiz assim, vou continuar fazendo assim, o livro me oferece isto e está bom" (Excerto extraído da entrevista semiestruturada, E1, 2014). Nosso próximo questionamento foi: "[...] como esses docentes trabalhariam a pesquisa (que faria parte de seu cotidiano), tendo em vista sua insatisfação?”. O quadro seguinte traduz a resposta: 
Quadro 15. Excertos 14

A primeira questão é a desacomodação, suponhamos que todos na graduação desenvolveram um trabalho de conclusão, hoje muitos dos nossos professores fizeram uma pós-graduação, eles têm uma noção, mas precisam aprofundar. Porque ele o professor não pode pedir ao aluno para ser um pesquisador se ele não pesquisa também (Excerto extraído da entrevista semiestruturada, E1).

Fonte: Dados organizados pelas pesquisadoras, 2014

Ainda na entrevista, lemos ao professor a seguinte frase: "A incorporação da pesquisa na prática pedagógica é a garantia da construção de novos conhecimentos" (RIO GRANDE DO SUL, 2011-2014) e perguntamos: Quem garante? Que garantia? Que conhecimentos? Para ele:

\section{Quadro 16. Excertos 15}

Primeira questão é da base teórica que vem de uma práxis realizada de uma experiência experimentada e constatada, por isso que a teoria nos ampara, nos dá a direção e ela nos diz que a pesquisa desperta curiosidade, nós precisamos de vários conhecimentos, saberes, para conseguir chegar a uma síntese de um determinado tema quando vamos fazer isto na prática é desta forma que irá acontecer. É muito diferente eu dar um teorema pronto, uma fórmula do que se ele vai construir. Quem vai garantir isto é o processo ser desenvolvido dentro desta forma correta e certa seguindo os passos e o professor tem que ter o conhecimento no mínimo básico de não exigir demais para este aluno que está iniciando (Excerto extraído da entrevista semiestruturada, E1).

Fonte: Dados organizados pelas pesquisadoras, 2014

Em sua enunciação o professor expressa preocupação com a teoria e a prática pedagógica, que perpassa por um fazer inserido na pesquisa. Já em outra entrevista perguntamos a E3: "Como você vê o princípio do ensino pela pesquisa motivado e orientado pelos professores?” O quadro 17 contém a resposta do professor em questão:

\section{Quadro 17. Excertos 16}

Você não consegue dar conta desse princípio através da ação pedagógica narrativa unilateral do professor que caracteriza o paradigma do cartesianismo, do positivismo e da física newtoniana que na realidade toda a educação foi organizada a partir desses referenciais. A escola, o funcionamento da escola, seus programas pré-definidos, com os pré-requisitos, com a seriação, isso tudo vem de uma lógica da física newtoniana que concebe o mundo como um relógio. Leis bem definidas e do cartesianismo e sua visão compartimentada da realidade e o positivismo que concebe o conhecimento como coisas prontas que estão aí e que podem ser apropriadas (Excerto extraído da entrevista semiestruturada, E3).

Fonte: Dados organizados pelas pesquisadoras, 2014

O professor $\mathrm{E}_{3}$ ainda declarou que "[...] então é necessário dar o salto da pedagogia onde o jovem é um paciente e um receptor para uma pedagogia onde ele o aluno é um ator, pesquisador, alguém que vai construir seu próprio conhecimento" (Excerto extraído da entrevista semiestruturada, 2014). "Seria essa a insegurança dos professores, isto é, conceber o aluno também como pesquisador?”, perguntamos. Na sequência, encontra-se mais um excerto relacionado a essa questão:

Quadro 18. Excertos 17

A pesquisa possibilita a compreensão da realidade em que os saberes não ficam na memória de curto prazo, adquire significado e começa a pertencer na formação intelectual do aluno (Excerto extraído da entrevista semiestruturada, E3).

Fonte: Dados organizados pelas pesquisadoras, 2014 
O citado docente também pontuou que "[...] para muitos a compreensão em torno da pesquisa ainda não é uma coisa clara, pouco conhecida" (Excerto extraído da entrevista semiestruturada, 2014). Seria essa mais uma insegurança dos professores? E3, ao finalizar, acrescentou: "Essa travessia que se tenta fazer e que dialoga com todo mundo científico e tecnológico nos dias de hoje" (Excerto extraído da entrevista semiestruturada, E3, 2014). Diante disso, sentimo-nos motivados a fazer outro questionamento: " $E$ como você vê hoje o professor enquanto pesquisador?" Para ele:

\section{Quadro 19. Excertos 18}

[...] a cultura e toda a inovação ela tem que criar cultura, onde as pessoas começam a ter comportamentos naturais, em relação àquilo que está se fazendo. Isso ainda não é uma realidade, isso é um processo, precisa de um tempo para consolidar, da cultura dos professores se veem como pesquisadores, e a pesquisa ser uma coisa natural dentro da Educação Básica, mas esse é o começo (Excerto extraído da entrevista semiestruturada, E3).

Fonte: Dados organizados pelas pesquisadoras, 2014

Ao analisarmos reportagens em dois jornais de circulação no Vale do Taquari/RS, entre elas, os excertos já apresentados, encontramos as que nos fizeram pensar sobre a formação do professor-pesquisador: "Vamos precisar de [...] oferta de cursos de formação continuada. Primeiro é preciso que os educadores mudem sua concepção de educação" (O INFORMATIVO, 07 out. 2011, p.31). Em outro texto, é possível ler a entrevista concedida por uma professora: "Toda a bagagem que tivemos e preparamos ao longo da carreira, não podemos mais passar para os alunos [...] agora, os professores precisam se aperfeiçoar em outras questões que envolvem o mercado de trabalho [...]" (O INFORMATIVO, 20 de ago. 2013, p. 11).

As enunciações apresentadas, retiradas da técnica de grupo focal, das entrevistas e dos jornais, mostram as incertezas, as (in) seguranças dos professores com a Proposta do Ensino Médio Politécnico, o que nos levou a procurar autores que teorizam em torno de desafios do ensino na contemporaneidade. Henz (2009, p. 68) expressou que "[...] trata-se do desafio de deformar, de abrir espaço na forma/fôrma, de tornar porosa a blindagem a que todos não só os futuros professores - estamos submetidos". Para ele, "[...] esses professores em formação pouco têm investido em estratégias de resistência que permitam introduzir mudanças nos funcionamentos conservadores" (HENZ, 2009, p. 68). A expressão resistência evidenciada por Henz (2009), bem como no referencial teórico que sustenta esta investigação, vem na ordem da criação e da produção de outras possibilidades de ensinar e aprender nos espaços escolares. Isso nos reporta a Gallo e Souza (2004, p. 27) quando afirmam que operar com os conceitos de Foucault é permitir que se organizem "táticas de resistência, de singularização, de diferenciação”.

Para os autores, essas resistências significam ir "contra as estratégias do ensino, do já sabido, opor as 
estratégias do ensino do ainda não pensado, do impensável" (GALLO; SOUZA, 2004, p. 27-28). A (in) segurança dos professores pode, então, produzir algo ainda não pensado para os processos de ensinar e de aprender na escola. Ou seja, com ela ou a partir dela, pode-se pensar em "experiências de diferença, experiências de resistência" (GALLO; SOUZA, 2004, p. 27-28). Essas reflexões nos remeteram a algumas palavras já citadas: 'insegurança', 'desafio', 'resistência', 'dúvida', 'medo'. Foucault (1979, p. 241), ao ser entrevistado por Bernard Henri Lévy, em Microfísica do poder, argumenta que

Esta resistência de que falo não é uma substância. Ela é anterior ao poder que ela enfrenta. Ela é coexistiva a ele e absolutamente contemporânea. [...]. Para resistir, é preciso que a resistência seja como o poder. Tão inventivo, tão móvel, tão produtiva como ele. Que, como ele, venha de baixo e se distribua estrategicamente. [...] a partir do momento que há uma relação de poder, há uma possibilidade de resistência. Jamais somos aprisionados pelo poder: podemos sempre modificar sua dominação em condições determinadas e segundo uma estratégia precisa (FOUCAULT, 1979, p. 241).

Como Foucault (1979), quando ele compara a resistência ao poder, compreendemos que este não perpassa pela lógica da repressão, mas é considerado uma rede produtiva que atravessa toda a sociedade. Portanto, "o que faz com que o poder se mantenha e que seja aceito é simplesmente que ele não pesa só como uma força que diz não, mas que de fato ele permeia, produz coisas, induz ao prazer, forma saber, produz discurso" (FOUCAULT, 1979, p. 8). Neste sentido, recorremos novamente a Foucault (2005, p. 20), quando ele afirma que,

[...] se quisermos compreender as coisas, se quisermos efetivamente compreendê-las em sua natureza, em sua essência e, portanto, em sua verdade, é necessário que nos abstenhamos de rir delas, de deplorá-las ou de detestá-las. Somente quando estas paixões se apaziguam podemos enfim compreender (FOUCAULT, 2005, p. 20).

Para Foucault, "compreender, não é nada mais que um certo jogo, ou melhor, o resultado de um certo jogo, de uma certa composição entre rir, deplorar e detestar" (2005, p. 21). No entanto, para ele, essas três paixões ou impulsos - rir, detestar e deplorar - não seriam uma maneira de aproximação do objeto, mas de "[...] conservar o objeto à distância, de se diferenciar dele ou de se colocar em ruptura com ele, de se proteger dele pelo riso, desvalorizá-lo pela 
deploração, afastá-lo e eventualmente destruí-lo pelo ódio" (FOUCAULT, 2005, p. 21). Dessa forma,

A educação, embora seja, de direito, o instrumento graças ao qual todo indivíduo, em uma sociedade como a nossa, pode ter acesso a qualquer tipo de discurso, é bem sabido que segue, em sua distribuição, no que permite e no que impede, as linhas que estão marcadas pela distância, pelas oposições e lutas sociais. Todo sistema de educação é uma maneira política de manter ou de modificar a apropriação dos discursos, com os saberes e os poderes que eles trazem consigo (FOUCAULT, 2012, p. 41).

Na mesma esteira teórica encontramos Veiga - Neto (2002) que afirma que grande parte dos profissionais da educação teve uma formação nos moldes iluministas, sendo uma das consequências "[...] as rápidas e profundas mudanças culturais, sociais, econômicas e políticas em que nos achamos mergulhados" (VEIGA - NETO, 2002, p. 23). Por conta disso, o autor sustenta que devemos "[...] desconfiar das bases sobre as quais se assentam as promessas e as esperanças nas quais nos ensinaram a acreditar" (VEIGA - NETO, 2002, p. 23). Mas “[...] que cada professor e cada professora não aceite automática e silenciosamente, de modo não problemático, as grandes declarações de princípio que vem há mais de 200 anos dando sustentação ao mundo moderno [...]" (VEIGA - NETO, 2002, p. 23).

Para o pesquisador, analisar os discursos - e, como neste trabalho, os discursos produzidos a partir da Proposta do Ensino Médio Politécnico - é ter sempre em vista que "[...] é por uma certa economia dos discursos de verdade que há possibilidade de exercício de poder" (VEIGA-NETO, 2007, p. 99). Os discursos sobre (in) segurança, assim como as expressões 'porto seguro', 'zona de conforto' nos remeteram às ideias de Veiga-Neto (2008, p.40), quando ele afirma que, "[...] a própria sociedade é defendida por crise". Ele acrescenta:

Ser moderno, mais do que marcar a vida num tempo determinado, daí para diante significou viver assombrado pelo conflito nascido de um esquecimento; a saber, o esquecimento de uma temporalidade dessacralizada, tornado humana, não tem lugar para a transcendência. Em suma, a crise vem a ser, justamente a manifestação do conflito ininterrupto entre as forças imanentes, construtivas e criadoras e o poder transcendente que visa a restaurar a ordem (VEIGA-NETO, 2008, p. 40).

As reflexões de Veiga-Neto acerca da crise da modernidade nos conduziram a pensar sobre o professor e, dessa forma, a algumas contribuições de Martins (2004, p. 116): 
[...] teríamos que atentar cada vez mais para as suas histórias de vida e formação, assegurando também a ele, professor, que pudesse manter seu direito à diferença, à liberdade de expressão, seu direito à resistência e, principalmente, assegurar que o professor não necessitasse abrir mão de sua cidadania plena para que um projeto ideal de cidadania dos estudantes seja colocado em prática (MARTINS, 2004, p. 116).

Tendo em vista as ideias de Martins, destacamos algumas palavras, como "diferença", "liberdade de expressão" e "resistência", que fizeram com que optássemos a citar a sua problematização: "Será que desejamos sair do espaço regular e normatizador da escola, para uma prática diluída e difusa de garantir diferenças em uma cultura comum?” (MARTINS, 2004, p. 116). Essa pergunta nos fez pensar o quanto as ações dos professores são controladas e controladoras, ou seja, há relações de poder e saber nos meios escolares. A pergunta da autora está em justamente sabermos se "[...] queremos, de verdade, deixar de controlar o professor e se eles querem, de fato, pagar o preço por esta autonomia" (MARTINS, 2004, p. 116). Para ela, as mudanças na forma de pensar e estruturar um currículo escolar e a tentativa de compreendê-lo geram, automaticamente, incertezas. Nessa tentativa, os nossos olhares "[...], necessitam do entendimento não apenas dos movimentos de resistência às mudanças, mas também das práticas conservadoras e tradicionais presentes, ainda, na ação docente" (MARTINS, 2004, p. 108).

\section{Para não finalizar: alguns pontos em suspenso}

Em tempos contemporâneos as evoluções científicas e tecnológicas, nas mais diferentes esferas da sociedade, são visíveis. Neste cenário as instituições de ensino da Escola Básica deparam-se diariamente com grandes desafios, sejam eles: aliar a pesquisa ao currículo escolar, ou seja, incorporar de fato a concepção de pesquisa ao dia a dia da escola. Conforme expresso neste trabalho, a resistência gerada pelos professores, de acordo com o pensamento foucaultiano, vem na ordem da produção e criação de algo novo para o ensino, e nesta reflexão por meio da pesquisa escolar. A (in) segurança dos docentes para trabalhar com a Proposta do Politécnico, em especial com a pesquisa escolar, seria a 'crise' de um tempo em que a segurança já nos deixou há muito tempo.

A (in) segurança dos professores se concentrava na pesquisa e nos modos de operar com ela na disciplina de Seminário Integrado. Nesta, a pesquisa era motivadora e orientadora para a construção de projetos de interesse do aluno. As enunciações dos entrevistados, durante a técnica 
de grupo focal, mostram que a pesquisa era desenvolvida apenas na disciplina de Seminário Integrado, não seguindo, portanto, o princípio pedagógico disposto nos Pareceres e Decretos para o Ensino Médio e, consequentemente, descrito na Proposta do Politécnico.

As mudanças propostas pela Secretaria de Educação, por meio dos documentos, são discursos daquela época, envolvidos em relações de poder e saber. Ao operarmos com algumas das ferramentas foucaultianas, percebemos que o discurso é uma produção histórica. As enunciações dos professores não podem ser compreendidas como simples manifestações do sujeito, mas na sua emergência, dispersão e descontinuidade. O sujeito do discurso e, aqui, em especial, o professor era, ao mesmo tempo, falante e falado, porque através dele havia outros ditos.

Na mídia, as manifestações dos professores sobre a nova configuração do Ensino Médio evidenciavam movimentos de insatisfação. A proposta configurava a exigência de profissionais atuantes, questionadores, criativos, proativos, capazes de construir autonomia intelectual e aprimorar as práticas. Caberia, nessa perspectiva, a esses profissionais da educação, investir tempo na busca constante dos saberes por meio da pesquisa visando ao seu aperfeiçoamento. Há, assim, muito a pesquisar sobre a temática.

Por meio desta escrita, desejamos também fomentar outras discussões acerca do assunto 'Ensino Médio Politécnico' e a '(in) segurança' gerada para operar com a Proposta, principalmente no que diz respeito à pesquisa escolar e à 'forma' como os professores trabalhavam com ela.

\section{Referências}

AHORA. Veja o que mudará com a reforma. 25-26-27 nov. 2011. abr. 2013 .

. Protesto mobiliza professores e alunos. 25

Politécnico mostra dilema em novo modelo de ensino. 22 ago. 2013.

BRASIL. Ministério da Educação. Secretaria de Educação Básica. Parecer CNB/CEB no 5/2011. Diretrizes Curriculares Nacionais para o Ensino Médio. Disponível em: <http://www4.planalto.gov.br/legislacao>Acesso em $\operatorname{dez} / 2013$.

CALVINO, Ítalo. Um general na biblioteca. São Paulo: Companhia das letras, 2010.

FOUCAULT, Michel. A ordem do discurso. Aula inaugural do Collège de France, pronunciada em 2 de dezembro 
de 1970. 22. ed. Tradução: Laura Fraga de Almeida Sampaio. São Paulo: Edições Loyola, 2012.

A verdade e as formas jurídicas. Rio de Janeiro: Editora NAU, 2005.

Microfísica do Poder. São Paulo: Editora Paz e Terra, 1979.

GALLO, Sílvio; SOUZA, Maria de Souza. Introdução. In: GALLO, Sílvio; SOUZA, Maria de Souza (Org). Educação do Preconceito. Ensaios sobre poder e resistência. Campinas, SP: Editora Alínea, 2004.p. 9-28.

HENZ, Alexandre de Oliveira. Formação de professores. In: AQUINO, Julio Groppa; CORAZZA, Sandra Mara (Orgs.). Abecedário: educação da diferença. Campinas: Papirus, 2009. p. 67-70.

JÉLVEZ, Julio Alejandro Quezada. A pesquisa como princípio pedagógico no Ensino Médio. In: AZEVEDO, José Clovis de; REIS, Jonas Tarcísio. Reestruturação do Ensino Médio: Pressupostos teóricos e desafios da prática. São Paulo: Fundação Santillana. 2013. p. 117-138.

A pesquisa nas práticas educativas do Ensino Médio. In: AZEVEDO, José Clovis de; REIS, Jonas Tarcísio. Reestruturação do Ensino Médio: Pressupostos teóricos e desafios da prática. São Paulo: Fundação Santillana. 2014. p. 155-184.

MARTINS, Maria do Carmo. E se o Outro é o professor? Reflexões acerca do currículo e histórias de vida. In: GALLO, Sílvio; SOUZA, Regina Maria de (Org). Educação e Educação do Preconceito. Ensaios sobre poder e resistência. Campinas, SP: Editora Alínea, 2004. p.103- 118.

O INFORMATIVO. Mudanças dependem de formação. 07 out. 2011.

Burburinhos e aplausos no discurso das mudanças. 04 nov. 2011.

Ensino Médio Politécnico: ainda é cedo para avaliar? 06 abr. 2013.

\footnotetext{
Alunos renegam Ensino Politécnico. 20 ago. 2013

RIO GRANDE DO SUL. Secretaria da Educação. Governo do Estado. Proposta Pedagógica para o Ensino Médio Politécnico e Educação Profissional Integrada ao Ensino Médio. 2011-2014.
}

VEIGA - NETO, Alfredo. Foucault e a Educação. 2. ed. Belo Horizonte. Autêntica. 2007. 
Crise da modernidade e invenções curriculares: da disciplina para o controle. Trajetórias e processos de ensinar e aprender: sujeitos, currículos e culturas. XIV ENDIPE. 2008. p. 35-58.

Olhares. In: COSTA, Marisa Vorraber. Caminhos investigativos. Novos olhares na pesquisa em educação. Rio de Janeiro: DP\&A, 2002. p. 23-38.

Recebido em: 04/07/2019 Aprovado em: 24/03/2020 Publicado em:01/04/2020 